\title{
Some Transport Properties of Alumix-431 Materials by Prepared P/M Method
}

\author{
Abdul Kadir EKSI ${ }^{1, *}$, Ayse Nur ACAR ${ }^{1}$, Ahmet Ekicibil ${ }^{2}$ \\ ${ }^{1}$ Department of Mechanical Engineering, Faculty of Engineering and Architecture, Cukurova University, Turkey \\ ${ }^{2}$ Department of Physics, Faculty of Sciences and Letters, Cukurova University, Turkey
}

Copyright $(\mathcal{C} 2015$ by authors, all rights reserved. Authors agree that this article remains permanently open access under the terms of the Creative Commons Attribution License 4.0 International License

\begin{abstract}
Thermoelectricity is referred to conversion waste heat into electricity or electricity into heat at temperature gradients. The efficiency of a thermoelectric generator is controlled via both the thermoelectric properties and the temperature decrease. Al 7xxx used in the aircraft, automoble industry have electrical and thermal conductivity, high strength, hardenable properties, and the $\mathrm{Al} 7 \mathrm{xxx}$ materials selected in this study have been produced by $\mathrm{P} / \mathrm{M}$ method; the thermoelectric properties of materials were measured. Max. Electrical resistivity and thermal conductivity were obtained $0.161 \Omega \mathrm{m}$ and $24.96 \mathrm{~W} / \mathrm{Km}$ respectively at $285-295 \mathrm{~K}$ temperature ranges. Seebeck coefficient is varied from negative sign to positive sign due to the carriers. Also max. figure of merit is determined $31.182 \times 10^{-9}$ at $93.610 \mathrm{~K}$ temperature.
\end{abstract}

Keywords Thermoelectricity, Al-7xxx Alloys, Thermoelectric Properties

\section{Introduction}

Thermoelectricity discovered by Thomas Seebeck in 1821 is means to convert waste heat into electricity energy at temperature gradients. By transisting waste heat produced from solar radiation, automobile, exhaust and industrial process to electricity through the thermoelectric power (TEP) of solids without generating greenhouse gas emission, thermoelectric (TE) generators could be play an important role. In addition TE refrigeration applications include coolers [1-5].

The operation principle of power generation and solid state cooling are based on the TE effects included Seebeck effect, Peltier Effect, Thomson Effect. This effects act on the producing electricity energy, measuring temperature, either heating or cooling objects. Seebeck Effect is a temperature difference along a conductor given increase to a potential difference ( $\mathrm{S}=\alpha=\Delta \mathrm{V} / \Delta \mathrm{T}$ where $\mathrm{S}$ is Seebeck coefficient, $\Delta \mathrm{V}$ is $\mathrm{TE}$ voltage and $\Delta \mathrm{T}$ is temperature difference.) Peltier effect described by Jean-Charles-Altanase Peltier in 1834, refers the carrying heat of carriers, when carriers flow through a conductance. Thomson effect developed by Lord Kelvin in 1851 is also defined the rate of heat produced and absorbed in a single carrying conductance exposed to a temperature gradient. This relationship states properties of three effects; therefore it is called as Figure of Merit [1-12].

$$
Z T=\frac{\alpha^{2} T}{\rho \kappa_{\text {total }}}=\frac{\alpha^{2} \sigma}{\kappa_{\text {total }}}=\frac{\alpha^{2} / L}{1+\frac{\kappa_{l}}{\kappa_{e}}}
$$

Table 1. Nomenclature of Thermoelectricity

\begin{tabular}{|c|c|}
\hline \multicolumn{2}{|c|}{ Nomenclature } \\
\hline ZT & Figure o merit (dimensionless) \\
\hline$\alpha$ & Seebeck coefficient \\
\hline $\mathrm{T}$ & Temperature (Kelvin) \\
\hline$\rho$ & Electrical Resistivity \\
\hline$\sigma$ & Electrical Conductivity \\
\hline$\kappa_{\text {total }}$ & Total Thermal Conductivity \\
\hline$\kappa_{\mathrm{e}}$ & Electronic Thermal Conductivity \\
\hline$\kappa_{\mathrm{l}}$ & Lattice Thermal Conductivity \\
\hline $\mathrm{L}$ & Lorenz Factor \\
\hline
\end{tabular}

The Lorenz factor is a constant only for materials and varies specially with carrier concentration. $\mathrm{ZT}$ is maximized as the Seebeck coefficient and the electrical conductivity increases and thermal conductivity decreases.

Alumix 431 alloy used in this study is known as Al-7xxx series alloys and widely used in aircraft structure, automobile industry because of their low density, high strength, hardness, outstanding workability [13-15]. Kverneland et al. [16] stated that the microstructure of high strength aluminum alloys consist of second phase particles, dispersoids and strengthening precipitates. The second phase particles generate from either the existence iron a silisium contaminants or excessive amount of major alloying elements. Dispersoids called as intermetallics particles occur from elements such as $\mathrm{Cr}, \mathrm{Zr}$ and $\mathrm{Mn}$, the elements have low 
possibility in $\mathrm{Al}$ at all temperatures. Homogenization plays a role o the precipitated dispersoid particles such as $\mathrm{Al}_{3} \mathrm{Zr}$ and spinule grain particles at high temperatures $\left(350-500^{\circ} \mathrm{C}\right)$ and for long times (6-24 times). Lastly, the base sequence of strengthening precipitates includes widely of $\mathrm{Mg}$ and $\mathrm{Zn}$ and this sequence is considerable to dominate hardenable process.
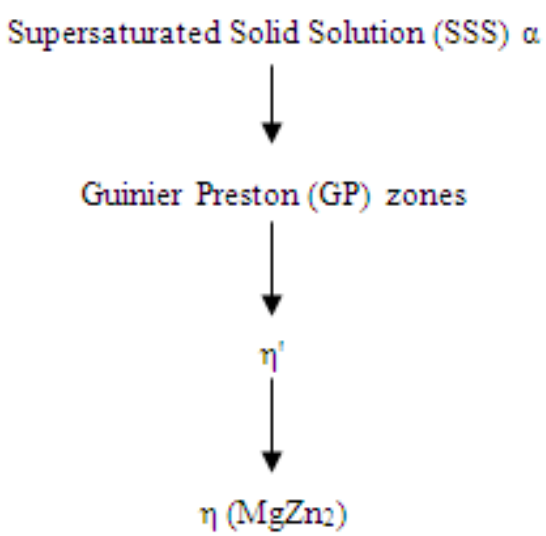

Zhang et al. [17] explained the $\eta$ phase is a quaternary phase generated from solid solution of $\mathrm{MgZn}_{2}$ with $\mathrm{AlCuMg}$ components (ie $\operatorname{Mg}(\mathrm{Zn}, \mathrm{Al}, \mathrm{Mg})_{2}$ or $\mathrm{Mg}\left(\mathrm{Zn}_{2} \mathrm{AlMg}\right.$ ) and a stable phase with known as crystal structure. Pseudo-hexagonal $\eta$ ' phase is produced from the second aging phase. Waterloo et al. [18] showed forth Aluminum alloys are alloyed with the elements $\mathrm{Zn}, \mathrm{Mg}, \mathrm{Cu}, \mathrm{Zr}$ formed the Al-7xxx series alloys and occurred precipitated of various ternary and quaternary compositions.

Guyot and Gottigines [19] expressed the investigating of the aging of $\mathrm{AlMgZnCu}$ alloys in a temperature range where the metastable phase $\eta$ ' precipitates homogeneously with a three-fold point of view utilizing the microstructural parameters and established the correlation with the electrical conductivity on the basis of a semi-phenomenological two-base model of electron scattering and the late conductivity increase ascribing to the precipitate coarsening at constant volume fraction [19].

Salazar-Guapuriche et al. [20] supplied a material (aluminum alloy 7010) as a plate produced from a sheet via a complex thermo-mechanical process. Authors investigated the structural and thermoelectrical properties such the tensile strength and proof strength, hardness and electrical conductivity of $\mathrm{Al}$ alloy 7010 under various temper and ageing conditions, to correlate strength with hardness and electrical conductivity. They established the acceptably linear relationship between the strength and hardness, spite of the reasonably nonlinear relationship between hardness and strength with electrical conductivity and stated the opposite effect between electrical conductivity and hardness in the natural and over ageing conditions. They also realized the overall raising trend for both hardness and electrical conductivity owing to the constitution of the coherent and semicoherent precipitates $\left(\mathrm{MgZn}_{2}\right)$ in the preternaturally aged condition.

Ferragut et al., investigated the early stages of pre-aging at near room temperature in an $\mathrm{Al}-\mathrm{Zn}-\mathrm{Mg}-\mathrm{Cu}$ based commercial alloy via electrical resistivity. They sufficiently defined the resistivity changes in the same terms of a Johnson-Mehl-Avrami (JMA) type function. This function is necessitated for the volume fraction growth of the Guinier-Preston zones or pre-precipitate solute clusters constituted [21-22].

In this study, we have been investigated the thermoelectric properties of $\mathrm{Al} 431$ material produced from powder metallurgy, such as electrical conductivity, electrical resistivity with Seebeck coefficient, figure of merit.

\section{Experimental Procedure}

Material used in this study was Alumix 431® powder from Ecka Granules in Germany. It is a mixture of 7xxx series aluminium alloys, termed Alumix 431. The chemical composition and particle size characteristics of Alumix 431 powders used in this study are given in Table 1. The specimens were compacted in a cylindrical die of $15 \mathrm{~mm}$ diameter to give compacts of about $15 \mathrm{~mm}$ in height, which has approximately a weight of $3.5 \mathrm{~g}$ with an accuracy of $0.001 \mathrm{~g}$ for static properties. This allowed good density distribution in the compact and reduced die wall friction, even though no lubricant was separately used. They were pressed up between 300 and $400 \mathrm{MPa}$ pressure with $50 \mathrm{MPa}$ intervals.

The Alumix 431 series alloy is based on additions of zinc, magnesium and copper and the material is a high strength alloy. Zinc is dissoluble in aluminum, important alloying addition for Alumix 431 and supports to the precipitation hardening [23-24]. Feng et al. [25] expressed that a practical limit of about $8 \mathrm{wt} \% \mathrm{Zn}$ is implemented for traditional cast materials due to intrinsic foundry problems like solute macrosegregation and cracking. Copper is doped to these alloys to enhance the wetting behavior of the liquid phase of aluminum and also supports to precipitation hardening as Zinc element [23-24]. Both copper containing and zinc containing aluminum alloys possess a high strength/weight ratio and have been extensively implemented in aerospace, automotive, textile engineering etc. Really, zinc effect on the strength of aluminum alloy is more important compared to effect of copper.

Xue et al. [26] stated that the Al-7xxx alloys are sensitive to localize corrosion because of the existence of strengthening phases such as $\mathrm{MgZn}_{2}, \mathrm{AlMg}_{3} \mathrm{Zn}_{2}, \mathrm{Al}_{3} \mathrm{CuMg}$. Mola [27] said the $\mathrm{Mg}$ is the lightest material and indicates superior properties such as high dimensional stability and thermal conductivity, good formability and recyclability. Spite of its advantages, there is a major disadvantage of $\mathrm{Mg}$ element as inadequate corrosion resistance because of high reactivity. $\mathrm{Mg}$ and its alloys are also qualified via low hardness and wear resistance, so their useful areas are restricted to mechanical parts working under static conditions such as casing, housing. Magnesium even at $0.5 \%$ 
level, have positive effect on shrinkage via decreasing the oxide, permitting metal/metal contact at particle interfaces and facilitating diffusion [23-24].

Table 2. Chemical composition and particle size characteristics of the Alumix 431[23]

\begin{tabular}{|c|c|c|c|}
\hline \multicolumn{2}{|c|}{$\begin{array}{c}\text { Chemical Comp. \% density 2.718 } \\
\text { g/cm }\end{array}$} & \multicolumn{2}{c|}{ Particle Size Distribution $(\mu \mathrm{m})$} \\
\hline $\mathrm{Al}$ & 89 & $\mathrm{D}_{10}$ & 54.8 \\
\hline $\mathrm{Cu}$ & 1.5 & $\mathrm{D}_{50}$ & 107.2 \\
\hline $\mathrm{Mg}$ & 2.5 & $\mathrm{D}_{90}$ & 193.1 \\
\hline $\mathrm{Zn}$ & 5.5 & ${ }^{*} \mathrm{~S}_{\mathrm{w}}$ & 4.7 \\
\hline Lubricant & 1.5 & Mean Value & 18.2 \\
\hline
\end{tabular}

*Dimensions are in $\mu \mathrm{m}$,

$* * \mathrm{~S}_{\mathrm{w}}$ : The particle size distribution slope.

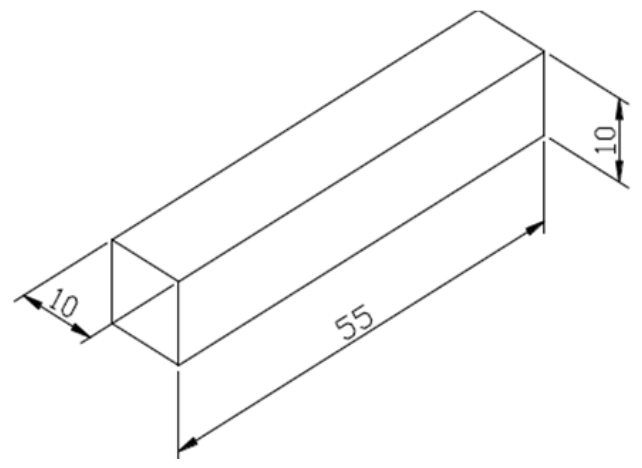

Figure 1. The Specimen used in this study before cutting

The specimens cut to investigate the thermoelectric properties in Scientific and Technologic Center, İnönü University, Malatya, Turkey (D 2-5mm).

\section{Results and Discussions}

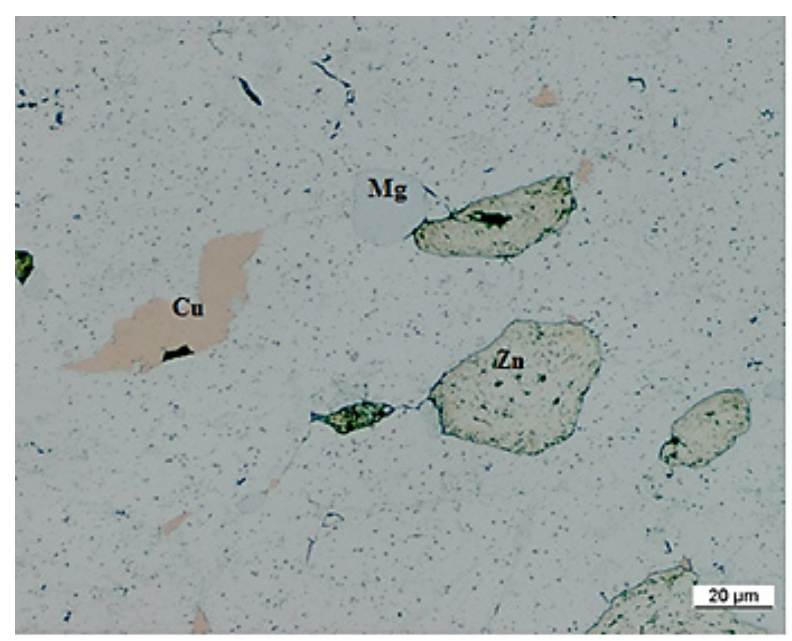

Figure 2. Optical microscope image of alumix (431) sample with materials $(20 \mu \mathrm{m})(350 \mathrm{MPa} / \mathrm{RT})$ (Alumix 1)

In the Figure 2, micrographs of green parts and sintered parts of the powders utilized in this study is indicated the alloying elements, particle boundaries and porosities on the green compact.

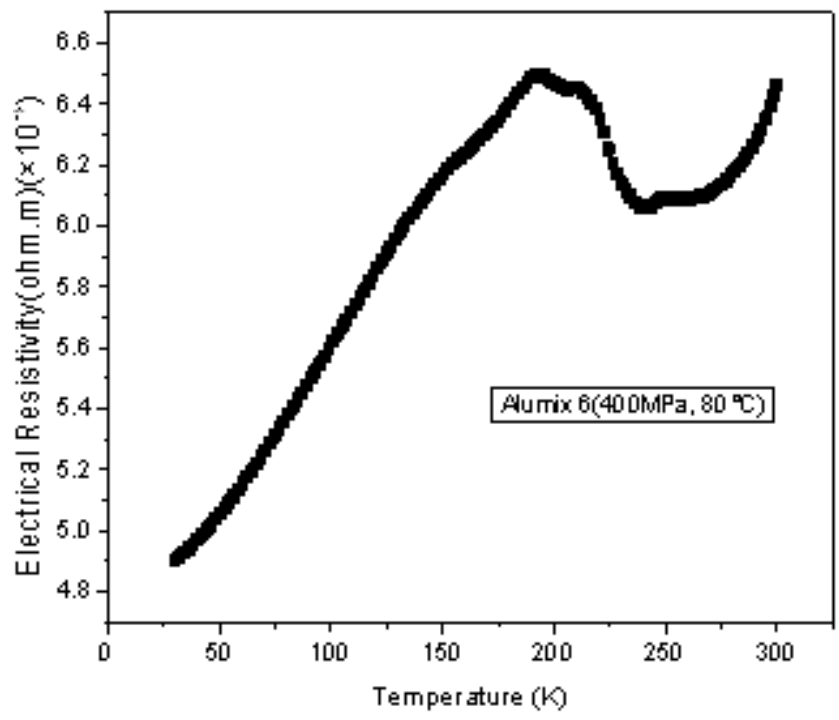

Figure 3. The Resistivity-Temperature curve of alumix (431) 6

In alumix 6 (at temperature range 200-265K), the decrease in alumix (431) system is explained lowers the resistivity of from $6.450 \times 10^{-4} \Omega \mathrm{m}$ (at $205.05 \mathrm{~K}$ ); $6.0621 \times 10^{-4} \Omega \mathrm{m}($ at $242.02 \mathrm{~K}) ; 6.095 \times 10^{-4} \Omega \mathrm{m}($ at $263.50 \mathrm{~K})$, respectively, and produces a metallic conductors shown in Figure 3. According to the study of Carlini et al. [28] these observings show that within these temperature ranges, there is a composition attribute that obtained semiconducting features while metallic behavior is sighted on both sides of these ranges.

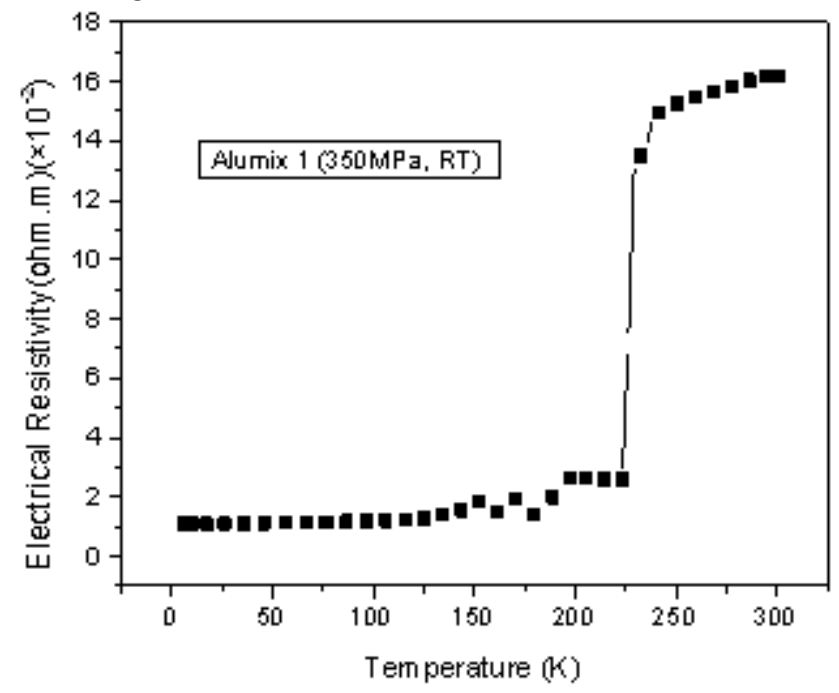

Figure 4. The Resistivity-Temperature graph of alumix(431) 1

In alumix 3 sample, it is indicated that an abrupt jump due to the structural transition at temperature $225 \mathrm{~K}$ (see in Figure 4). The abrupt change is resulted from the impurity phases developed in the main matrix and weak intergranular matchup. The existence of impurity phases, weak intergranular matchup and Alumix (431) grains play important role in decreasing the transition temperature $\left(\mathrm{T}_{c}\right)$ [29-30]. 


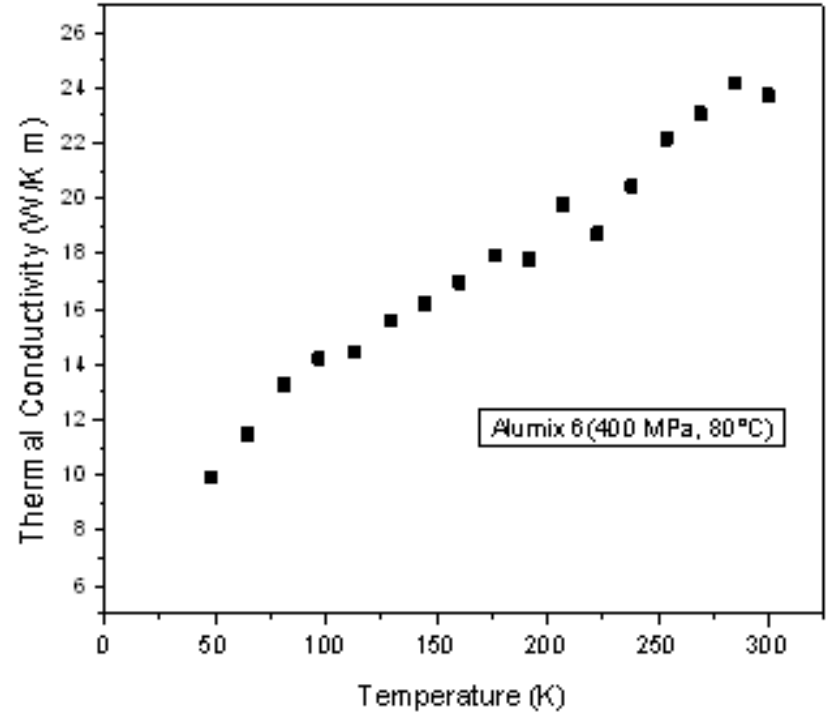

Figure 5. The Thermal conductivity -Temperature graph of alumix (431) 6

For Figure 5, in Alumix 1 sample, at 290-300K, it was exhibited the rising from $17.806 \mathrm{~W} / \mathrm{Km}$ (at $191.7 \mathrm{~K}$ ) and $18.720 \mathrm{~W} / \mathrm{Km}$ (at $222.49 \mathrm{~K}$ ). It is considered the reason of the rapid increasing of $\kappa$ occur from the increase of phonon mean free path electrons intensify into the copper pairs or the electron contribution. Below transition temperature $\left(T_{c}\right)$, the rapid increase of $\kappa$ indicates improvement of the quasiparticle contribution the heat conductivity in regard to article of Aksan et al. [30].

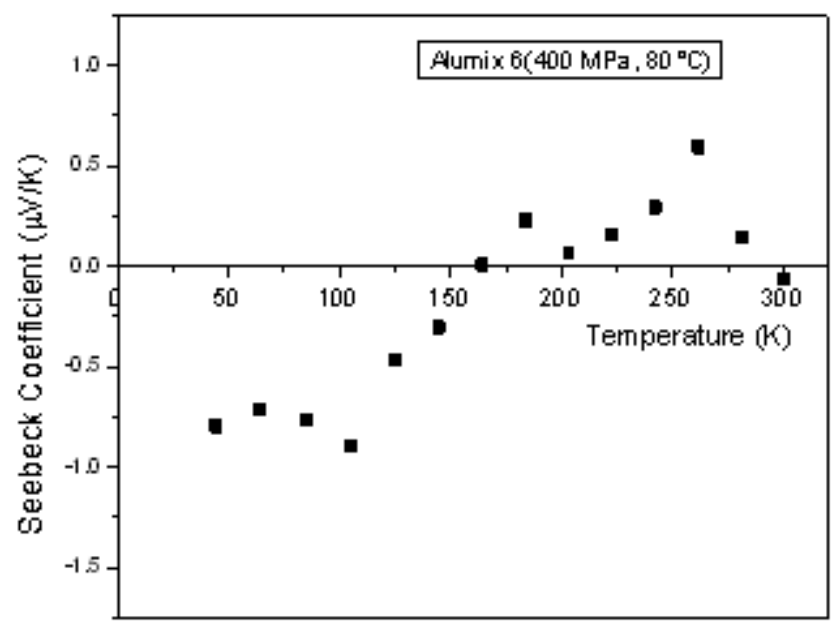

Figure 6. The Seebeck coefficient -Temperature graph of alumix (431) 1

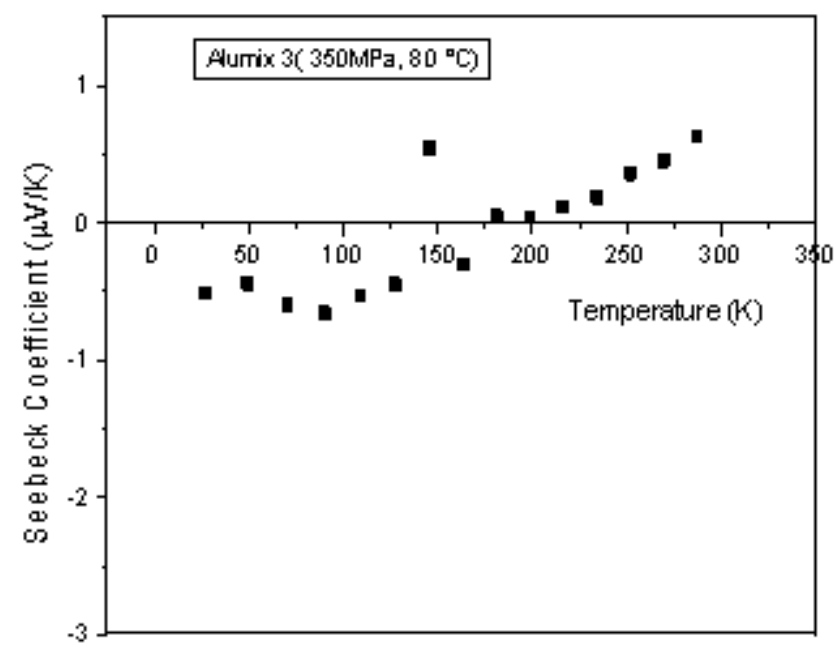

Figure 7. The Seebeck coefficient-Temperature graph of Alumix (431) 3

With reference to the Park et al.' study[31], In alumix 6-3 samples illustrated in Figures 6-7, the Seebeck coefficient sign indicates positive value at temperature from $50 \mathrm{~K}$ to room temperature due to the possessing the holes which are the major conductivity carriers. Seebeck coefficient is increased, when the more acute spreading carriers as the temperature is increase. Due to a rapid increase in carrier concentration with the increasing of the temperature the Seebeck coefficient decreases at 150-175K.

According to the study of He et al. [32], higher Seebeck coefficient is acquired in higher porosity specimen. It is considered effect of the grain size, on the increasing of the Seebeck coefficient. When the number of both impurities and point flaws within grains slant to increase through the decreasing of the grain boundaries, with the rising spreading of carriers resulted via impurities and flaws, Seebeck coefficient increases.

In the Figure 8; for alumix 4 specimens, it was showed that ZT decreases because of the increase of thermal conductivity and it was determined the highest ZT of $31.182 \times 10^{-9}$ at 93.610 K due to improvement of Seebeck coefficient such the study of Han et al. [33]. According to the Pan et al.'s article [34], samples show valleys at the temperature $130-190 \mathrm{~K}$ (for alumix 5) due to $\eta \rightarrow \eta$ ' phase transition. Also, it is preponderated with different effects such as larger thermal conductivity, smaller Seebeck coefficient, though its electrical resistivity is improved. 


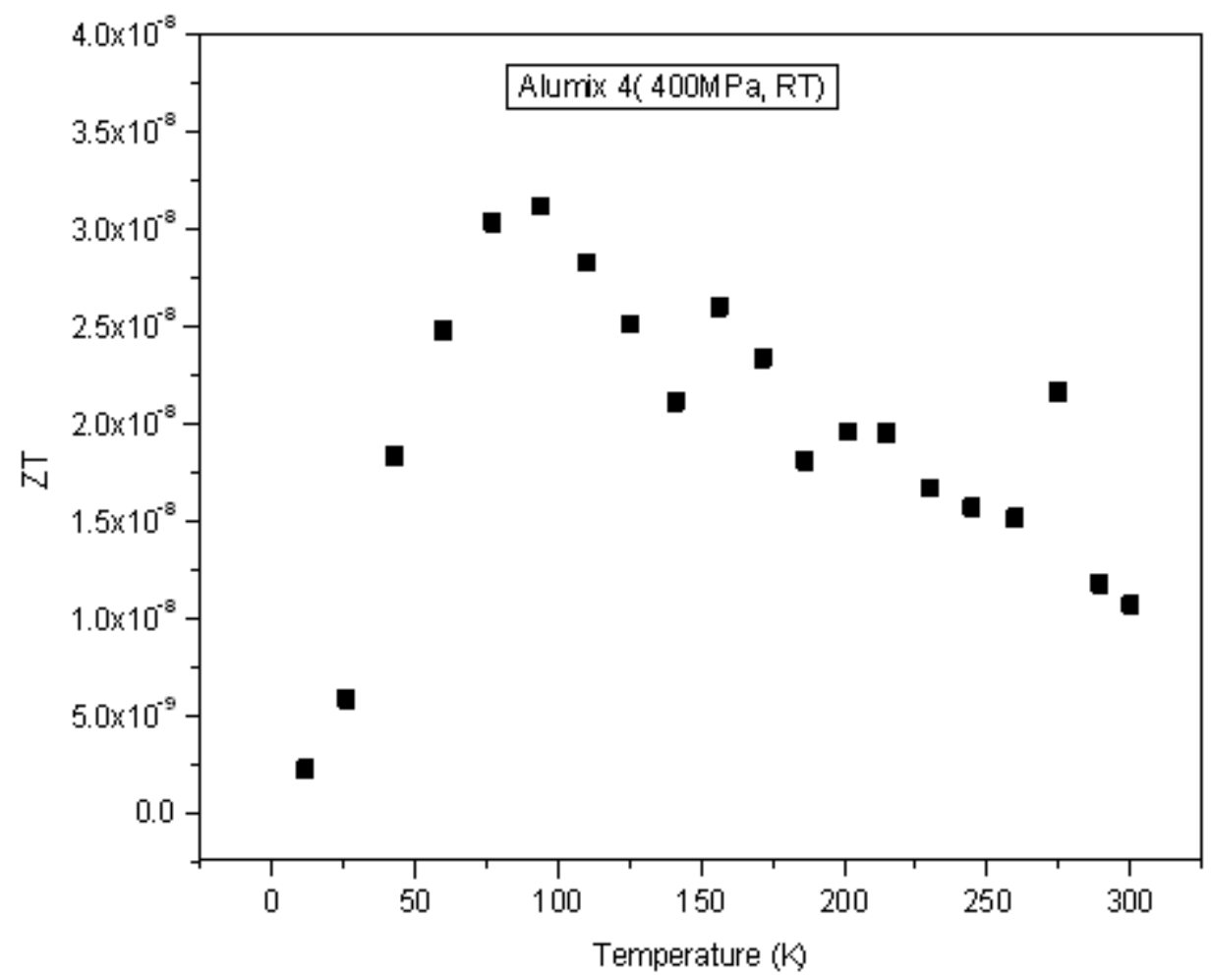

Figure 8. The ZT-Temperature graph of alumix (431) 5

\section{Conclusions}

In this study, the physical and thermoelectrical properties of the specimens applied to aircraft industry and prepared by $\mathrm{P} / \mathrm{M}$ method were investigated. Maximum electrical resistivity is obtained from $0.161 \Omega \mathrm{m}$ because of gaining metallic property at $285-295 \mathrm{~K}$ temperature ranges. Maximum thermal conductivity is attained $24.96 \mathrm{~W} / \mathrm{Km}$ at 285-295K due to increased the phonon mean free path. The variation from negative sign to positive sign of Seebeck coefficient is resulted from existence of carriers. Maximum figure of merit value is originated from the phase transition and higher porosity and determined as $31.182 \times 10^{-9}$ at 93.610K temperature.

\section{Acknowledgements}

This study was supported by Cukurova University Research Foundation ÖYP2090.

\section{REFERENCES}

[1] G. J. Snyder, E. S. Toberer, Complex Thermoelectric Materials, Nature Materials, Vol 7, February 2008

[2] Netzch Thermoelectric Materials Applications Brochure, Online available from

https://www.netzsch-thermal-analysis.com/en/materials-appl ications/thermoelectric/

[3] T. M. Tritt, Thermoelectric Materials: Principles, Structure, Properties, and Applications, Encyclopedia of Materials: Science and Technology, pp. 1-11, 2002

[4] A. Bulusu, D.G. Walker, Review Of Electronic Transport Models For Thermoelectric Materials, Superlattices and Microstructures 44, 1-36, 2008

[5] J.-C. Zheng, Recent Advances on Thermoelectric Materials, Front. Phys. China, , 3(3): 269-279, 2008

[6] S. Yamanaka, H. Kobayashi, K. Kurosaki, Thermoelectric Properties Of Layered Rare Earth Copper Oxides, Journal of Alloys and Compounds 349,321-324, 2003

[7] P.X. Zhang, G. Y. Zhang, C.T. Lin, H.U. Habermeier, New Thermoelectric Materials And New Applications, Egypt. J. Sol., Vol. (27), No. (1), 2004

[8] G. Chen, M. S. Dresselhaus, G. Dresselhaus, J.-P. Fleurial, T. Caillat, Recent Developments In Thermoelectric Materials, International Materials Reviews Vol. 48 No. 1, 2003

[9] W. Park, M. T. Barako, A. M. Marconnet, M. Asheghi, K. E. Goodson, Effect of Thermal Cycling On Commercial Thermoelectric Modules, Thermal and Thermomechanical Phenomena in Electronic Systems (ITherm), 2012 13th IEEE Intersociety Conference on Pages 107-112 Publisher IEEE, $2012 / 5 / 30$

[10] T. M.Tritt, M.A. Subramanian, H. Böttner, T. Caillat, G. Chen, R. Funahashi, X. Ji, M. Kanatzidis, K. Koumoto, G. S. Nolas, J. Poon, A. M. Rao, I. Terasaki, R.Venkatasubramanian, J. Yang, Thermoelectric Materials, Phenomena, And Applications: A Bird's Eye View, Mrs Bulletın ,Volume 31, March 2006 
[11] R. Venkatasubramanian, E. Siivola, T. Colpitts and B. O'quinn, Thin-Film Thermoelectric Devices With High Room-Temperature Figures Of Merit, Nature ,Vol 413, 11 October 2001,

[12] H. Zhou, Efficiency Of Inhomogeneous Thermoelectric Generators, Applied Mathematical Sciences, Vol. 4 (no. 11), 505-514, 2010

[13] S.F. Fang, M.P. Wang, M. Song, an Approach for the Aging Process Optimization of $\mathrm{Al}-\mathrm{Zn}-\mathrm{Mg}-\mathrm{Cu}$ Series Alloys, Materials and Design, Vol. 30, 2460-2467, 2009

[14] Y. Jia, F. Cao, Z. Ning, S. Guo, P. Ma, J. Sun, Influence Of Second Phases On Mechanical Properties Of Spray Deposited $\mathrm{Al}-\mathrm{Zn}-\mathrm{Mg}-\mathrm{Cu}$ Alloy, Materials and Design, Vol. 40, 536-540. 2012

[15] Y. Liu, D. Jiang, B. Li, W. Yang, J. Hu, Effect of Cooling Aging on Microstructure and Mechanical Properties of an $\mathrm{Al}$ $\mathrm{Zn}-\mathrm{Mg}-\mathrm{Cu}$ Alloy, Materials and Design, Vol. 57, 79-86, 2014

[16] A. Kverneland, V. Hansen, G. Thorkildsen, H.B. Larsen, P. Pattison, X.Z. Li, J. Gjønnes, Transformations and Structures in the Al-Zn-Mg Alloy System: A Diffraction Study Using Synchrotron Radiation and Electron Precession, Materials Science and Engineering: A, Vol. 528, 880-887. 2011

[17] F.P. Zhang, Q.M. Lu, J.X. Zhang, Synthesis and High Temperature Thermoelectric Properties of $\mathrm{Ba}_{\mathrm{x}} \mathrm{Ag}_{\mathrm{y}} \mathrm{Ca}_{3-\mathrm{x}-\mathrm{y}} \mathrm{Co}_{4} \mathrm{O}_{9}$ Compounds, Journal of Alloys and Compounds, Vol. 484, 550-554, 2009

[18] G. Waterloo, V. Hansen, J. Gjønnes,S.R. Skjervold,. Effect Of Predeformation And Preaging At Room Temperature In Al-Zn-Mg- $(\mathrm{Cu}, \mathrm{Zr})$ Alloys, Material Science And Engineering A, Vol. 303, 226-233, 2001

[19] P. Guyot, L. Cottignies, Precipitation Kinetics, Mechanical Strength and Electrical Conductivity of $\mathrm{AlZnMgCu}$ Alloys, Acta Materialia, Vol. 44, 4161, 4167, 1996.

[20] M.A. Salazar-Guapuriche, Y.Y. Zhao, A. Pitman,A. Greene, Correlation of Strength with Hardness and Electrical Conductivity for Aluminum Alloy 7010, Materials Science Forum, Vol. 519-521, 853-858, 2006.

[21] R. Ferragut, A. Somoza, A. Tolley, Microstructural Education of 7012 Alloy during the Early Stages of Artificial Ageing, Acta Materialia, Vol. 47 No. 17, 4355-4364, 1999.

[22] R. Ferragut, A. Somoza,I. Torriani, Pre-Precipitation Study in the $7012 \mathrm{Al}-\mathrm{Zn}-\mathrm{Mg}-\mathrm{Cu}$ Alloy by Electrical Resistivity, Materials Science and Engineering: A, Vol. 334, 1-5, 2002.
[23] A. Ekși, G. Veltl, F. Petzoldt, K. Lipp, C.M. Sonsino, Tensile And Fatigue Properties Of Cold And Warm Compacted Alumix 431 Alloy, Powder Metallurgy, 200A, Vol.47 No.1, 2004

[24] O. İynen, A.K. Ekşi, D.A. Bircan, , Effect Of Shot Peening Process On Alumix 431 Powder Materials, Ç.Ü., Müh.-Mim.Fak. Dergisi, Haziran/Aralık 2010, Cilt 25, Sayı $1-2,2010$

[25] W. Feng, X. Baiqing, Z. Yongan, L. Hongwei H. Xiaqing, Microstructural Development of Spray-deposited Al-Zn-Mg-Cu Alloy During Subsequent Porosity, Journal of Alloys and Compounds 477, 616-621, 2009

[26] W. Xue, C. Wang, H. Tian Y. Lai,, Corrosion Behaviours and Galvanic Studies of Microscopic Oxidation Films on Al-Zn-Mg-Cu Alloy, Surface and Coatings Technology 201: 8695-8701, 2007

[27] R. Mola, Fabrication and Microstructural Characterization of $\mathrm{Al} / \mathrm{Zn}$ - Enriched Layers on Pure Magnesium, Materials Characterization 78, 121-128, 2013

[28] R. Carlini , D. Marré, I. Pallecchi , R. Ricciardi, G. Zanicchi, Thermoelectric properties of $\mathrm{Zn}_{4} \mathrm{Sb}_{3}$ intermetallic compound doped with Aluminum and Silver, Intermetallics 45 (60-64), 2014

[29] M.A. Aksan, A. Güldeste, Y. Balcı,b M.E. Yakınc1, Degradationof Superconducting Properties in $\mathrm{MgB}_{2}$ by $\mathrm{Cu}$ Addition, Solid State Communication 137: 320-325, 2006

[30] M.A. Aksan, S. Altin, Y. Balci, M.E. Yakinci, ,Structural Characterization and Transport Properties of the HTc $\mathrm{Bi}_{2} \mathrm{Sr}_{2}(\mathrm{Ca}, \mathrm{Cd}) \mathrm{Cu}_{2} \mathrm{O}_{8+\delta}$ Glass-Ceramic Rods, Materials Chemistry and Physics 106: 428-436, 2007

[31] K. Park, K.Y. Yo, J.K. Seong, S. Nahm, ,Microstructure and High-Temperature Thermoelectric Properties of Polycrystalline $\mathrm{CuAl}_{1-\mathrm{x}} \mathrm{Mg}_{\mathrm{x}} \mathrm{O}_{2}$ Ceramics, Journal of European Ceramic Society 27, 3735-3738, 2007

[32] Z. He, D. Platzek, C. Stiewe, H. Chen, G. Karpinski, E. Müller, Thermoelectric Properties of Hot-pressed Al- and Co-doped Iron Disilicide Materials, Journal of Alloys and Compounds 438: 303-309, 2007

[33] Y. M. Han, Z. Chen, C. Xin, Y. Pei, M. Zhou, R. Huang, L. Li, Improved Thermoelectric Performance of Nb-doped Lead Selenie, Journal of Alloys and Compounds 600: 91-95, 2014

[34] L. Pan, X.Y., Qin, H.X. Xin, C.J. Song, Q.Q. Wang, J.H. Sun, R.R. Sun, Effect of Silicon Condition on Thermoelectric Properties of Bulk $\mathrm{Zn}_{4} \mathrm{Sb}_{3}$ at Low Temperatures, Solid State Science 12: 1511-151 5,2010 